CLINICAL STUDY

\title{
Psychoses associated with thyrotoxicosis - 'thyrotoxic psychosis.' A report of 18 cases, with statistical analysis of incidence
}

\author{
B E W Brownlie ${ }^{1}$, A M Rae ${ }^{2}$, J W B Walshe ${ }^{2}$ and J E Wells ${ }^{3}$ \\ ${ }^{1}$ Department of Nuclear Medicine, Christchurch Hospital, ${ }^{2}$ Psychological Medicine, Christchurch Hospital and ${ }^{3}$ Department of Public Health and \\ General Practice, Christchurch School of Medicine, Christchurch, New Zealand \\ (Correspondence should be addressed to B E W Brownlie, Department of Nuclear Medicine, Christchurch Hospital, Christchurch, New Zealand)
}

\begin{abstract}
Objective: To report a series of newly diagnosed thyrotoxic patients with concurrent acute psychosis, and to assess the association between the two disorders.

Design: Retrospective study of thyrotoxic patients with associated psychosis ('thyrotoxic psychosis'; TP) requiring inpatient psychiatric care. New Zealand thyrotoxicosis annual incidence figures and first psychiatric admission rates for affective psychosis were utilised to statistically assess the co-occurrence of thyrotoxicosis and affective psychosis.

Patients and Methods: During the 20-year study period, 18 inpatients (16 women and 2 men), mean age 54 years, with TP were identified. No patient had a past history of thyrotoxicosis, but four had required psychiatric inpatient care many years earlier. Thyrotoxicosis was documented by radioimmunoassay of thyroid hormone levels, and thyroid scintiscan. Psychiatric manifestations were classified using ICD9 criteria.

Results: Thyroid hormone levels were markedly elevated in more than half of our TP patients. All younger patients had Graves' disease, and most older patients toxic nodular goitre. All patients were treated with antithyroid drugs, and all but one subsequently received ${ }^{131}$ I therapy. Two patients were not mentally ill when thyrotoxicosis was diagnosed, but suffered major mood swings when thyroid hormone levels were falling. There was no specific psychiatric clinical picture but affective psychoses were commonest - seven depression, seven mania. The other diagnoses were two schizophreniform, one paranoid, and one delirium. Initially, neuroleptic medication was used in all but one patient, and during long-term follow-up (median 11 years) more than half our series had remained well with no further psychiatric problems. Statistical analysis was restricted to thyrotoxic patients with first psychiatric hospital admission for affective psychosis. During the 20-year period, there were nine thyrotoxic patients $(95 \%$ confidence interval $4.5-17.1)$ with concurrent affective psychosis requiring first admission, and the calculated expected number was only 0.36 . These findings indicate a clear association well above chance co-occurrence.

Conclusion: TP is not a specific clinical picture, but affective psychoses are commonest. Statistical analysis of thyrotoxic patients with concurrent affective psychoses showed an incidence well above chance co-occurrence. It appears that thyrotoxicosis may be a precipitant of acute affective psychosis.
\end{abstract}

European Journal of Endocrinology 142 438-444

\section{Introduction}

Thyrotoxic patients frequently suffer from psychological difficulties, and occasionally psychiatric features predominate and the patient presents with an acute psychosis. Although anecdotal case reports of psychological illnesses associated with thyrotoxicosis continue to be published (1), most medical texts do not mention psychosis as a presenting feature of thyrotoxicosis. In contrast, psychosis associated with hypothyroidism, 'myxoedema madness', is generally accepted (2).
More than 150 years ago, von Basedow first described a psychotic illness, probably mania, in a patient with exophthalmic goitre (3). More recent case reports have emphasised depressive (4), manic (5), paranoid (6) and schizophreniform features (3). Psychotic reactions associated with hyperthyroidism are uncommon and accurate incidence figures are not available (7). In some papers, the psychiatric illness has not been concurrent with thyrotoxicosis, and in earlier accounts documentation of hyperthyroidism has been suboptimal. Acute delirium reactions in older case reports were probably 
thyroid crises complicating acute infections (8), and currently thyroid crises are rare.

In the present report we document 18 patients who required inpatient care for acute psychosis associated with newly diagnosed thyrotoxicosis - 'thyrotoxic psychosis' or TP. In 16 patients, the psychiatric illness occurred in untreated thyrotoxicosis, and in two patients psychosis developed within weeks of commencing antithyroid medication when thyroid hormone levels were falling. In the proportion of our thyrotoxic patients with concurrent affective psychosis, we have assessed the association utilising local annual incidence figures for thyrotoxicosis (9), and psychiatric hospital first admission rates for affective psychosis.

\section{Patients and methods}

Eighteen patients with newly diagnosed thyrotoxicosis requiring inpatient psychiatric care were accumulated over a 20-year period (1974-1993). The names of 14 of the 18 patients had been noted at presentation by one of the authors (BEWB), and the remaining four patients were identified by reviewing letters of discharged thyroid clinic patients (1974 onwards, held in Department of Nuclear Medicine). The original psychiatric and thyroid clinic case notes were reviewed for clinical and biochemical data. All discharge psychiatric diagnoses were assessed and, where necessary, diagnoses between 1974-1979 were reclassified by the psychiatrist authors using strict International Statistical Classification of Diseases and Related Health Problems, ninth revision (ICD9) criteria.

Sixteen of the 18 patients were psychiatrically ill when first referred to a thyroid clinic. The remaining two patients were not mentally ill when first seen, but required inpatient care for acute psychosis within weeks of commencing antithyroid medication. The 16 patients with concurrent newly diagnosed thyrotoxicosis and psychosis included 13 referred from psychiatric wards, one surgical inpatient (acute frontal sinusitis) subsequently transferred to a psychiatric ward, one patient initially seen at a thyroid clinic who refused medication and was later admitted to a psychiatric ward to commence antithyroid and neuroleptic drugs, and one manic patient managed in a general medical hospital. Excluded from the study were five psychiatric inpatients with newly diagnosed thyrotoxicosis - three patients undergoing alcohol withdrawal, and two patients with dementia. Also excluded were newly diagnosed thyrotoxic patients with previously diagnosed ongoing manic-depressive psychosis, schizophrenia, or other major psychiatric illness.

Thyrotoxicosis was documented by radioimmunoassay of serum thyroxine $\left(\mathrm{T}_{4}\right)$, free thyroxine index $\left(\mathrm{FT}_{4} \mathrm{I}\right)$, serum tri-iodothyronine $\left(\mathrm{T}_{3}\right)$, pertechnetate gamma camera thyroid $\left({ }^{99 \mathrm{~m}} \mathrm{Tc}\right)$ scans; and, since 1987, sensitive thyrotrophin (TSH) measurements have also been made.

\section{Statistical methods}

Our thyroid clinic is a referral centre for the North and Mid-Canterbury areas (formerly administered by the North Canterbury Area Health Board). The region had a total population of 372948 at the 1986 census and was assumed to be approximately constant throughout the period (population growth was only $2 \%$ between the 1981 census and 1986). The annual incidence of thyrotoxicosis in the area is known for the period 1983-1985 - 25.8 per 100000 (female 40.7; male 10.5) (9).

The association between thyrotoxicosis and acute psychosis was investigated statistically only for the largest subgroup, namely those with affective psychoses. There were very few with other diagnoses and diagnostic criteria for these had changed markedly over the period, so reported admission rates could not be used.

It was possible to evaluate the co-occurrence of newly diagnosed thyrotoxicosis and first psychiatric hospital admission for affective psychosis by using figures from annual Mental Health Data Reports (Ministry of Health, New Zealand Health Information Service, Wellington). In the period 1980-1987, the rate of first admission for affective psychosis (ICD9) was 15 per 100000 females, and 11 per 100000 males; after the clinical revision of ICD9 in 1988, the rates rose to 22 per 100000 females and 15 per 100000 males. Rates for 1974-1979 were taken to be the average of those for the next 6 years; the reported rates were not used because they were based on ICD8. Rates for 1992 were used for 1993 as 1993 rates were not available. The age range used was $15-74$ years as both disorders are rare below 15 years, and in some psychiatric admission data there was an open upper category of 75+ years. Assuming independence, expected numbers with both thyrotoxicosis and affective psychosis were calculated for each age-sex grouping for each calendar year and summed (age was grouped in 10-year intervals). Confidence intervals for the observed number of patients were obtained from a table of confidence intervals for a Poisson distribution (Documenta Geigy Scientific Tables, edn 6).

\section{Results}

The age, sex and thyroid function data are summarised in Table 1. The 18 patients included 16 females and two males, and the mean age was 54 years (range 23-70 years). Sixteen were Caucasian, one Maori and one Fijian Indian. No patient had a past history of thyrotoxicosis, and only one had a family history of thyrotoxicosis. Ten of the 18 patients had severe thyrotoxicosis (serum $\mathrm{T}_{3}>9 \mathrm{nmol} / \mathrm{l}, \mathrm{FT}_{4} \mathrm{I}>350$ ). Thyroid scintiscans showed 11 patients to have diffuse hyperplasia, six toxic multinodular goitres, and one toxic nodule. All six patients under 30 years of age had diffuse hyperplasia, whereas six of the seven patients over 60 had toxic nodular goitres. Diagnosis of thyrotoxicosis 
Table 1 Thyroid function results, and treatment for 18 thyrotoxic patients (male $(\mathrm{M})$ and female $(\mathrm{F})$ ) with associated psychosis. Cases $1-16$, in chronological order 1974-1993, presented with concurrent thyrotoxicosis and psychosis, and Cases 17 and 18 only became mentally ill when thyroid hormone levels fell after the commencement of antithyroid medication.

\begin{tabular}{|c|c|c|c|c|c|c|}
\hline Case & $\begin{array}{c}\text { Sex/Age } \\
\text { (years) }\end{array}$ & $\begin{array}{c}\text { Serum } \mathbf{T}_{4} \\
(55-140 \mathrm{nmol} / \mathrm{l})\end{array}$ & $\begin{array}{c}\mathbf{F T}_{\mathbf{4}} \mathbf{I} \\
(55-160)\end{array}$ & $\begin{array}{c}\text { Serum } \mathbf{T}_{3} \\
(1.2-2.8 \mathrm{nmol} / \mathrm{l})\end{array}$ & $\begin{array}{l}{ }^{99 m} \mathrm{Tc} \\
\text { scan }\end{array}$ & Treatment \\
\hline 1 & F54 & 247 & 399 & & MNG & ${ }^{131} \mathrm{I}$ \\
\hline 2 & M65 & 160 & 248 & & MNG & 131 \\
\hline 3 & F24 & 310 & 803 & $>12$ & $\mathrm{D}$ & 131 I \\
\hline 4 & $\mathrm{~F} 27$ & 198 & 479 & 3.1 & $\mathrm{D}$ & $\begin{array}{l}\text { Antithyroid drugs for } 1 \text { month and } \\
\text { long-term lithium }\end{array}$ \\
\hline 5 & F58 & 220 & 576 & 5.1 & D & 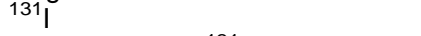 \\
\hline 6 & F23 & 140 & 203 & 4.1 & $\mathrm{D}$ & Thyroidectomy, ${ }^{131}$ I \\
\hline 7 & F70 & 222 & 484 & 2.8 & TUG & 131 | \\
\hline 8 & F68 & 218 & 231 & 2.5 & MNG & Antithyroid drugs ${ }^{*}$ \\
\hline 9 & F26 & 213 & 730 & 4.1 & D & Antithyroid drugs, ${ }^{131}$ I \\
\hline 10 & F68 & 210 & 298 & 2.0 & MNG & $131 \mathrm{I}$ \\
\hline 11 & F69 & 185 & 211 & 3.2 & MNG & 131 j \\
\hline 12 & F44 & 170 & 243 & 4.7 & $\mathrm{D}$ & 131 | \\
\hline 13 & M23 & 308 & 499 & $>12$ & $\mathrm{D}$ & 131। \\
\hline 14 & F69 & & $t$ & $\ddagger$ & MNG & 131 j \\
\hline 15 & F53 & 167 & 210 & 3.5 & $\mathrm{D}$ & 131 | \\
\hline 16 & F66 & 164 & 218 & 3.8 & $\mathrm{D}$ & 131 \\
\hline 17 & F48 & $206(113)$ & $375(85)$ & $4.2(1.7)$ & D & ${ }^{131} \mid$ \\
\hline 18 & F54 & $190(<10) \|$ & $483(<10)$ & $9.3(0.2)$ & $\mathrm{D}$ & ${ }^{131}$ I; two doses \\
\hline
\end{tabular}

${ }^{99 m}$ Tc scan: D, diffuse hyperplasia; MNG, toxic multinodular goitre; TUG, toxic uninodular goitre.

${ }^{*}$ Patient died of septicaemia after 4 weeks treatment; $\dagger$ free $\mathrm{T}_{4}: 35$ (N 10-25) pmol///; $\ddagger$ free $\mathrm{T}_{3}: 8(\mathrm{~N} \mathrm{2-5)} \mathrm{pmol} / \mathrm{l}$.

Results in brackets for Cases 17 and 18 were obtained when psychotic after antithyroid drugs.

\|TSH: $1.3(<5) \mathrm{mU} / \mathrm{l}$.

was made relatively early during admission, but a significant delay in diagnosis occurred in one patient Case 6 was initially considered to be suffering from puerperal depression, and it was not until her second psychiatric admission 4 months later that thyrotoxicosis was diagnosed.

The treatment of hyperthyroidism is summarised in Table 1. All 18 patients were initially treated with thionamide antithyroid medication. The mild antithyroid action of lithium carbonate played a dual role in five patients - both as a mood stabiliser and as an adjunct to carbimazole by blocking thyroid hormone secretion (10), and three patients received propranolol therapy. After the patients were euthyroid and psychiatric features controlled, all patients were recommended to consider definitive therapy for thyrotoxicosis. Most patients received radioiodine ${ }^{131} \mathrm{I}$ in moderate dosage $(>10 \mathrm{mCi})$ to minimise the need for retreatment, but the youngest patient opted for thyroidectomy. All 16 patients who received ${ }^{131} \mathrm{I}$ were commenced on $\mathrm{T}_{4}$ replacement when TSH levels were found to be persistently more than twice normal $(>10 \mathrm{mU} / \mathrm{l})$ to avoid overt hypothyroidism which could precipitate a psychiatric relapse.

Two patients chose to avoid definitive therapy for thyrotoxicosis. Case 9 received a 12-month course of carbimazole as she was fearful of radiation therapy, but she has suffered two further depressive episodes requiring inpatient care associated with thyroid dysfunction - the second episode after 6 months was precipitated by iatrogenic hypothyroidism due to carbimazole, and the third episode associated with a relapse of thyrotoxicosis occurred 12 months after completing a 1-year course of carbimazole. She was then treated with radioiodine, and she remains well on $\mathrm{T}_{4}$ replacement therapy with no further psychiatric problems in the subsequent 11 years.

All 18 patients required inpatient care, with seven patients hospitalised compulsorily under the Mental Health Act, and the median inpatient stay was 4 weeks (range 6 days to 10 weeks). The psychiatric features at presentation and diagnoses using ICD9 criteria are summarised in Table 2. In three patients treated in the 1970s, the original diagnoses were reclassified (Cases 3, 6 and 9 had previously been classified as having schizophrenia or schizo-affective disorder). The majority of patients were classified as having an affective psychosis - mania in seven, and major depression in seven. Less common were schizophreniform psychoses in two, paranoid psychosis in one, and delirium (associated with septicaemia) in one. The two male patients both attempted suicide - Case 2 took an overdose of tricyclic antidepressant tablets, and Case 13 threatened to jump from a window ledge. In addition to the psychiatric features listed in Table 2, many of our patients also showed typical hyperthyroid psychological symptoms anxiety, irritability, distractibility and insomnia.

Past psychiatric histories and family history data are summarised in Table 3. Only two patients (Cases 2 and 12) had a close relative requiring psychiatric hospital 
Table 2 Psychiatric features at presentation in 18 patients with TP. Cases 1-16 with concurrent thyrotoxicosis and psychosis, and Cases 17 and 18 only became mentally ill when thyroid hormone levels fell after the commencement of antithyroid medication.

\begin{tabular}{|c|c|c|c|c|c|c|c|}
\hline Case & Depression & $\begin{array}{c}\text { Suicidal } \\
\text { behaviour }\end{array}$ & Mania & $\begin{array}{l}\text { Paranoid } \\
\text { symptoms }\end{array}$ & Delusions & Hallucinations & Clinical picture \\
\hline 1 & & & + & + & + & & Mania \\
\hline 2 & + & + & & & + & & Depression \\
\hline 3 & & & & & + & + & Schizophreniform psychosis \\
\hline 4 & & & + & & + & & Mania \\
\hline 5 & & & + & + & + & + & Mania \\
\hline 6 & + & & & & & & Depression \\
\hline 7 & & & + & + & + & & Mania \\
\hline 8 & & & & & & + & Delirium \\
\hline 9 & + & & & + & + & & Depression \\
\hline 10 & + & & & + & + & + & Depression \\
\hline 11 & & & & + & + & + & Schizophreniform psychosis \\
\hline 12 & + & & & & & & Depression \\
\hline 13 & & + & + & & & & Mania \\
\hline 14 & + & & & & & & Depression \\
\hline 15 & & & & + & + & + & Paranoid psychosis \\
\hline 16 & & & + & & + & + & Mania \\
\hline 17 & + & + & & + & + & + & Depression \\
\hline 18 & & & + & & + & & Mania \\
\hline
\end{tabular}

admission. Four of the 18 patients had previously required inpatient psychiatric care, but this had been many years previously. Two of these four previous admissions had been with postpartum depression more than 20 years previously, and a further patient gave a history of two mild postpartum depressions not requiring drug therapy. Only one patient had a long history of unstable mood, and no patient had suffered a previous manic episode. Past psychiatric notes were not available for Case 11 who had spent some weeks in a private psychiatric hospital in another region some 15 years earlier, and she was the only patient in our series to have been seen by a psychiatrist in the preceding 20 years.

Significant life events might have contributed to the development of psychiatric disorder in two patients death of spouse and sibling respectively. Case 13, a young male, had a 5-year history of symptoms of hyperthyroidism, and of antisocial behaviour resulting in imprisonment.

Psychiatric treatment is summarised in Table 3. Neuroleptic medication was administered to all but one patient; seven patients received antidepressant therapy, five patients received lithium (long-term in one), and only one patient received electro-convulsive therapy (ECT). No patient required cardiology consultation for cardiac side-effects of psychotrophic medications, but two patients (Cases 5 and 17) suffered temporary impairment of cognition due to medication.

Psychiatric outcome is included in Table 3. The median duration of follow-up was 11 years (range 3-19 years). More than half of the patients have remained well without further psychiatric problems, and only two patients have required long-term psychiatric supervision - Case 4 with multiple manic episodes unrelated to thyroid dysfunction, and Case 17 with persistent depression. One patient (Case 9 noted above) was readmitted twice with depression associated with thyroid dysfunction, and two patients have been readmitted with depression unrelated to thyroid dysfunction - Cases 2 and 12, the only patients in the series with a family history of psychoses. The two patients with schizophreniform psychosis remain well, and the patient with paranoid psychosis remains in the community, but with persistent paranoid ideation. The patient with antisocial behaviour has not re-offended during 6 years follow-up.

\section{Statistical analysis: co-occurrence of thyrotoxicosis and affective psychosis}

The statistics available were for first psychiatric hospital admissions for affective psychosis. Therefore we excluded three of the 14 patients with affective psychosis: two with previous psychiatric inpatient care more than 20 years earlier, and one managed in a general medical hospital (Case 16). In addition, we excluded the two patients who only became psychotic when their thyroid hormone levels were falling. Thus, in the 20-year period 1974-1993, there were nine patients (95\% confidence interval (CI) 4.12-17.09) who presented for first psychiatric admission with affective psychosis and concurrent thyrotoxicosis. During this 20 years the expected number (calculated from our thyrotoxicosis incidence and affective psychosis admission rates) was only 0.36 for the number of patients who would, in the same year, both suffer from thyrotoxicosis and be admitted for the first time to a 
Table 3 Family and past history of psychiatric disorder; psychiatric treatment and follow-up for 18 patients with TP.

\begin{tabular}{|c|c|c|c|c|c|c|c|}
\hline \multirow[b]{2}{*}{ Case } & \multirow[b]{2}{*}{ Past history } & \multirow[b]{2}{*}{ Family history } & \multicolumn{4}{|c|}{ Treatment } & \multirow{2}{*}{$\begin{array}{l}\text { Psychiatric } \\
\text { follow-up }\end{array}$} \\
\hline & & & Neuroleptic & Anti-depressant & Lithium & ECT & \\
\hline 1 & & & + & & & & Well for 18 years§ \\
\hline 2 & & Brother - depression & + & + & + & & $\begin{array}{l}\text { One further } \\
\text { depression; well }\end{array}$ \\
\hline 3 & & & + & & & & Well \\
\hline 4 & & & + & & + & & $\begin{array}{l}\text { Six further manias; } \\
\text { long-term } \\
\text { neuroleptic and Li }\end{array}$ \\
\hline 5 & PPD 27 years earliert & & + & & + & & $\begin{array}{l}\text { One mild depressive } \\
\text { episode; well }\end{array}$ \\
\hline 6 & & & + & & & & Well \\
\hline 7 & $\begin{array}{l}\text { Depression } 22 \text { years } \\
\text { earlier†¥ }\end{array}$ & & + & & & & Well \\
\hline $\begin{array}{r}8 \\
9 \\
10\end{array}$ & & & $\begin{array}{l}+ \\
+ \\
+\end{array}$ & + & & & $\begin{array}{l}\text { Died of septicaemia } \\
\text { Well }^{*} \\
\text { Well }\end{array}$ \\
\hline 11 & $\begin{array}{l}\text { Psychiatric admission } 15 \\
\text { years earlierll }\end{array}$ & & + & & & & Well \\
\hline 12 & $\begin{array}{l}\text { Two mild PPDs, no } \\
\text { reoccurrence }\end{array}$ & $\begin{array}{l}\text { Father - brief psychotic } \\
\text { episode }\end{array}$ & & + & & + & $\begin{array}{l}\text { One further } \\
\text { depression; well }\end{array}$ \\
\hline $\begin{array}{l}13 \\
14\end{array}$ & & & $\begin{array}{l}+ \\
+\end{array}$ & + & + & & $\begin{array}{l}\text { Well } \\
\text { Well }\end{array}$ \\
\hline 15 & & & + & & & & $\begin{array}{l}\text { Paranoid, in } \\
\text { community }\end{array}$ \\
\hline 16 & $\begin{array}{l}\text { Long-standing unstable } \\
\text { mood } \pi\end{array}$ & & + & & + & & Unstable mood \\
\hline 17 & & $\begin{array}{l}\text { Brother - alcoholic and } \\
\text { depressive features }\end{array}$ & + & + & & & $\begin{array}{l}\text { Remained } \\
\text { depressed; ECT } 1 \\
\text { year later }\end{array}$ \\
\hline 18 & PPD 28 years earlier† & $\begin{array}{l}\text { Mother - depressed in } \\
\text { later years }\end{array}$ & + & + & & & Well ${ }^{* *}$ \\
\hline
\end{tabular}

* Two relapses associated with thyroid dysfunction; †ECT; $¥$ mood unstable previous 6 years; $\|$ private clinic diagnostic information not available; $\uparrow$ low-dose tricyclic for $>20$ years; $\S$ further manic episode 18 years later in context of dementia; ${ }^{* *}$ mood swings during first 12 months while thyroid function unstable and two ${ }^{131}$ I doses required; anti-depressant and lithium (Li) continued for 6 of 9 years follow-up. PPD, postpartum depression.

psychiatric institution with affective psychosis. Thus the expected number of cases would have to be more than ten times that calculated to fall inside the 95\% confidence interval. The association of untreated thyrotoxicosis and first admission for affective psychosis was significant both for women (seven cases, 95\% CI 2.8114.42 , expected 0.31 ), and for men (two cases, $95 \% \mathrm{CI}$ 0.24-7.22, expected 0.05). These findings indicate a clear association which is well above the level of chance co-occurrence.

\section{Discussion}

The present series of patients with TP documents the spectrum of major psychiatric illnesses associated with newly diagnosed thyrotoxicosis. The psychiatric illnesses were severe, and almost half of our psychiatric inpatients were legally committed to hospital. Psychiatric diagnoses were made according to ICD9 criteria and our patients were not merely suffering the usual psychiatric disturbances of hyperthyroidism. There is no specific psychiatric picture but affective psychoses predominated with mania as common as depression. We suggest that thyrotoxicosis should be added to the list of metabolic causes of acute mania. Although major depression in thyrotoxicosis is uncommon, one study of consecutive hyperthyroid patients showed that almost one third fulfilled Diagnostic and Statistical Manual of Mental Disorders, edn 3 - Revised (DSM-IIIR) criteria for depression (11). None of our depressed patients could be described as suffering from 'apathetic thyrotoxicosis' and they would more aptly be described 
as having agitated depression. In our series, paranoid features were common, but only one patient had a paranoid psychosis. The two patients described as suffering from 'schizophreniform psychosis' had no family history of schizophrenia, and at long-term follow-up gave no evidence of major psychiatric illness. Criminal behaviour associated with thyrotoxicosis has been the subject of a previous report where thyrotoxicosis was adduced unsuccessfully as an explanation in defence of the patient's antisocial behaviour (12). Our only patient with delirium was suffering from undiagnosed septicaemia - this patient, and a second patient with concurrent infection, did not show features of thyroid crisis.

Two patients in our series (Cases 17 and 18) did not show psychotic behaviour when they presented with thyrotoxicosis, but suffered severe mood swings (mania or depression) within weeks of commencing carbimazole. In one of the two patients, thyroid hormone levels had dropped dramatically into the subnormal range while, in the second, thyroid hormone levels were normal when she became psychotic. Such acute psychiatric disturbances developing as thyroid hormone levels fall have been previously documented, but are not well known to clinicians (13). Perhaps better appreciated is the association of psychosis with rapid thyroid hormone replacement in hypothyroidism (14). These psychoses may be compared with postpartum psychoses which also follow acute hormonal changes. It is of interest that three of the 12 female patients with affective psychoses in our series gave a past history of postpartum depression and one can speculate as to whether there may have been postpartum thyroid dysfunction involved.

Patients with affective psychoses constitute the majority of our TP series, and the statistical analysis of patients with first admission for affective psychosis and concurrent newly diagnosed thyrotoxicosis indicates an association well above chance co-occurrence. In one patient, three episodes of depression were clearly related to thyroid dysfunction and a causal association seems beyond doubt. No statistical analysis was possible for our other smaller psychiatric subgroups. Earlier investigators considered that between 10 and $20 \%$ of hyperthyroid patients were mentally ill (7), but these reports antedate adequate thyroid function testing and modern psychiatric diagnostic criteria. Our TP series represents a 20-year experience from an area with known thyrotoxicosis incidence (9), and this suggests about $1 \%$ of thyrotoxic patients are first diagnosed with a major psychiatric illness. In future, prospective studies using current ICD10 or DSM-IV criteria may provide a more definitive assessment of concurrent psychosis and thyrotoxicosis.

The clinical diagnosis of thyrotoxicosis in patients with concurrent severe psychiatric symptoms is difficult, especially in mania. It has been local policy for more than 20 years to check thyroid function $\left(\mathrm{FT}_{4} \mathrm{I}\right)$ routinely during acute psychiatric admissions and our series would support this approach. The value of such routine laboratory investigation of acute psychiatric patients continues to be the subject of debate; a British study concluding that only thyroid function testing and urine cultures were of value, and then only in females (15). When blood samples are drawn within the first days of admission, transient hyperthyroxinaemia is not uncommon, and it has been suggested that testing be best left until the second week (16). The significance of elevated $\mathrm{FT}_{4} \mathrm{I}$ levels can be further assessed by measuring serum $\mathrm{T}_{3}$ and sensitive TSH on the same serum sample. Currently the alternative approach using 'TSH first' screening has not found favour in psychiatric settings, and in recent reports transient TSH elevation is more common than TSH suppression $(17,18)$.

Thionamide antithyroid medication should be commenced only following documentation of hyperthyroidism by more than one blood sample and preferably after a ${ }^{99} \mathrm{~m}$ Tc pertechnetate thyroid scan to document thyroid pathology. When euthyroidism is achieved and the psychiatric symptoms controlled, definitive radioiodine therapy can be recommended to prevent possible recurrent thyrotoxicosis and associated psychosis. However, patients may be unduly suspicious about radiation so that reassurance and education are vital. If lithium therapy is still necessary this can be continued during ${ }^{131}$ I therapy as lithium can be helpful by prolonging intrathyroidal ${ }^{131}$ I retention (19). If a patient with TP wishes to avoid radioiodine, long-term carbimazole is the alternative but this seems best combined with $\mathrm{T}_{4}$ to avoid iatrogenic hypothyroidism (Case 9 had recurrent psychosis with hypothyroidism). Our experience suggests that definitive high-dose radioiodine is the treatment of choice, followed by early $\mathrm{T}_{4}$ replacement.

Major tranquillisers were administered to all but one patient and none suffered significant side-effects. Seven patients received haloperidol without significant side-effects; but haloperidol has been reported to cause severe dystonia in hyperthyroid patients (20), and may have played some role in the induction of thyroid storm in one case report (21). In our retrospective study, it is not possible to distinguish the relative roles of neuroleptic therapy and antithyroid drug control of hyperthyroidism in suppressing the psychiatric features. Most patients had received neuroleptics for more than a week prior to commencing antithyroid medication, and one patient had a course of ECT. Biochemical euthyroidism was achieved in 4-6 weeks of commencing carbimazole in the majority of patients, and this helped considerably and facilitated discharge to community care.

Although the present series has provided better clinical and laboratory documentation of TP, it does not further our understanding of the underlying pathophysiology. Patients presenting with TP may have a constitutional vulnerability to major psychiatric 
disturbance, and genetic factors could play some part, but only two patients in our series had a family history of psychosis. In thyrotoxicosis, non-specific electroencephalogram abnormalities have been documented; one study showed that they may not be completely reversible, and further longitudinal studies are needed (22). There is recent evidence that subclinical thyrotoxicosis may be associated with affective disorders (18) but, in our thyrotoxic patients, thyroid hormone abnormalities were marked. Possible mechanisms could involve excess thyroid hormone affecting neurotransmitters (serotonin, $\gamma$ aminobutyric acid and dopamine), or second messengers (adenyl cyclase and phospholipase-C systems) (23). Further studies in laboratory animals are needed, and in humans it is possible that 'metabolic brain scanning' with magnetic resonance imaging or positron emission tomography could provide clues to the pathophysiology.

\section{References}

1 Jadresic DP. Psychiatric aspects of hyperthyroidism. Journal of Psychosomatic Research 199034 603-615.

2 Asher R. Myxoedematous madness. British Medical Journal 1949 ii 555- 562.

3 Greer S \& Parsons V. Schizophrenia-like psychosis in thyroid crisis. British Journal of Psychiatry 1968114 1357-1362.

4 Taylor JW. Depression in thyrotoxicosis. Americal Journal of Psychiatry $1975132552-553$.

5 Lee S, Chow CC, Wing YK, Leung CM, Chiu H \& Chen CN. Mania secondary to thyrotoxicosis. British Journal of Psychiatry 1991 $159712-713$.

6 Khuan TC. Psychoses associated with thyrotoxicosis: a retrospective study of twenty cases. Medical Journal of Malaysia 1985 40 247-251.

7 Bursten B. Psychoses associated with thyrotoxicosis. Archives of General Psychiatry 19614 267-273.

8 Dunlap HF \& Moersch FP. Psychic manifestations associated with hyperthyroidism. American Journal of Psychiatry 193591 1215-1238.

9 Brownlie BEW \& Wells JE. The epidemiology of thyrotoxicosis in New Zealand: incidence and geographical distribution in North Canterbury 1983-1985. Clinical Endocrinology 199033 249-259.
10 Hedley JM, Turner JG, Brownlie BEW \& Sadler WA. Low dose lithium-carbimazole in the treatment of thyrotoxicosis. Australian and New Zealand Journal of Medicine 19788 628-630.

11 Kathol RG, Turner R \& Delahunt J. Depression and anxiety associated with hyperthyroidism: response to antithyroid therapy. Psychosomatics 198627 501-505.

12 Davis PJ, Rappeport JR, Lutz JH \& Gregerman RI. Three thyrotoxic criminals. Annals of Internal Medicine 197174 743-745.

13 Bewsher PD, Gardiner AQ, Hedley AJ \& Maclean HCS. Psychosis after acute alteration of thyroid status. Psychological Medicine $19711260-262$.

14 Josephson AM \& MacKenzie TB. Thyroid-induced mania in hypothyroid patients. British Journal of Psychiatry 1980137 222-228.

15 White AJ \& Barraclough B. Benefits and problems of routine laboratory investigations in adult psychiatric admissions. British Journal of Psychiatry 1989155 65-72.

16 Spratt DI, Pont A, Miller MB, McDougall IR, Bayer MF \& McLaughlin WT. Hyperthyroxinemia in patients with acute psychiatric disorders. American Journal of Medicine 198273 $41-48$.

17 Chopra IJ, Solomon DH \& Huang TS. Serum thyrotrophin in hospitalised psychiatric patients: evidence for hyperthyrotropinemia as measured by an ultrasensitive thyrotrophin assay. Metabolism 199039 538-543.

18 Oomen HAPC, Schipperijn AJM \& Drexhage HA. The prevalence of affective disorder and in particular of a rapid cycling of bipolar disorder in patients with abnormal thyroid function tests. Clinical Endocrinology 199645 215-223.

19 Turner JG, Brownlie BEW \& Rogers TGH. Lithium as an adjunct to radioiodine therapy for thyrotoxicosis. Lancet $1976 \mathrm{i}$ 614-615.

20 Weiner MF. Haloperidol, hyperthyroidism, and sudden death. American Journal of Psychiatry 1979136 717-718.

21 Hoffman WH, Chodoroff G \& Piggott LR. Haloperidol and thyroid storm. American Journal of Psychiatry 1978135 484-486.

22 Perrild H, Hansen JM, Arnung K, Olsen PZ \& Danielsen U. Intellectual impairment after hyperthyroidism. Acta Endocrinologica $1986112185-191$.

23 Stern RA \& Prange AJ. Neuropsychiatric aspects of endocrine disorders. In Comprehensive Textbook of Psychiatry, edn 6, pp 241251. Eds HI Kaplan \& BJ Sadock. Baltimore: Williams \& Wilkins 1995.

Received 2 September 1999

Accepted 10 January 2000 